\title{
Agricultural Education Teacher Candidates' Reflection on the 15-Week Clinical Teaching Internship: A Collective Case Study
}

\author{
Christopher J. Eck ${ }^{\mathrm{a}}$, Jon W. Ramsey ${ }^{\mathrm{b}}$, Nathan Smith ${ }^{\mathrm{b}}$ \\ ${ }^{a}$ Clemson University, ${ }^{b}$ Oklahoma State University
}

\begin{abstract}
This collective case study explored the integration of video reflection during the 15 -week clinical teaching internship at three distinct points in time. Weeks three, seven, and 11 were investigated to determine if the integration of video reflection improved the quality of teacher candidate reflection and to gauge teacher candidates' views on agricultural education during the clinical teaching internship. Four overarching themes emerged from the video reflections: establishing roles as a teacher, teaching and learning, balance, and coming full circle. Throughout the internship, candidates expressed a deeper understanding of teaching within the three-component model of school-based agricultural education (SBAE). We recommend the use of video reflection during the student teaching internship to expand the depth of reflection and feeling of community among the cohort. Overall, the addition of the video reflection process has provided an efficient and effective tool that allows teacher candidates to make meaning of their experience.
\end{abstract}

Keywords: student teaching, video reflection, teacher preparation

\section{Introduction}

The agricultural education teacher preparation program at Oklahoma State University (OSU) is a nationally accredited educator preparation program. To that end, the program looks to the Council for the Accreditation of Educator Preparation (CAEP) for guidance regarding the design and implementation of the program; five standards guide the work of the program, of importance to this study was Standard 2: Clinical Partnerships and Practice. In an effort to "include technology-enhanced learning opportunities" (CAEP Standard 2.3, 2013), a video reflection was integrated into the weekly reflections submitted during the clinical internship to university supervisors. The investigation of these video reflections is supported by the American Association for Agricultural Education Research Agenda, Research Priority 5: Efficient and Effective Agricultural Education Programs (Roberts et al., 2016). 
The addition of a video reflection was intended to provide a more robust reflection on the clinical teaching internship. As Lambert et al. (2014) found, verbal interview reflections provide more depth with additional details not shared through written reflections. Reflection can take on many meanings, although Dewey (1933) defines it as an "active, persistent, and careful consideration of any belief or supposed form of knowledge in the light of grounds that support it and the further conclusions to which it tends to constitute reflective thought" (p. 118). Previous cohorts often provided a very narrow or shallow written reflection regarding the experience, which did not provide a process by which the teacher candidates could make meaning of the experience (Dewey, 1933). Given the dominant force technology plays in the lives of today's digitally-driven students (Giovannelli, 2003), a video reflection was added to the weekly report. To guide the reflection, candidates were to create a Swivl video highlighting their experiences. The video reflection process was selected as reflection plays a pivotal role in making meaning of an experience (Rodgers, 2002).

Reflection has become a common practice among teacher preparation programs (Epler et al., 2013; Greiman \& Covington, 2007; Retallick \& Miller, 2007, Sorensen et al., 2018), although the process by which teacher candidates reflect varies. Epler et al. (2013) implemented three different models of reflection among teacher candidates, i.e., written reflection, collaboratively written reflection, and think-aloud reflection. Greiman and Covington (2007) worked to identify the ideal structure for reflection through a journaling process of teacher candidates. Both studies found traditional written reflection to be less effective than other methods researched. Verbal reflection was the most popular reflection method found by Greiman and Covington (2007), followed by self-reflection, and finally written reflection. Similarly, Epler et al. (2013) found both think-aloud and collaborative methods to provide greater reflection than written reflection. Although many teacher preparation programs claim to be reflective, many do not meet the mark (Rodgers, 2002), leading to the need to be purposeful in the reflective nature of the clinical teaching internship. The implementation of weekly video reflections during the clinical teaching internship provides a focused verbal reflection with the intention of being more purposeful (Lambert et al., 2014).

\section{Theoretical/Conceptual Framework}

Teaching is defined as a series of professional decisions made before, during, and after interaction with students (Hunter, 2004). The skill of reflection is critical to the decision-making process described by Hunter when considering the development of teachers. The theoretical framework for this study relied on Schön's (1983) theory of experiential learning and reflective practice. The construction of domain-specific knowledge i.e., school-based agricultural education (SBAE) through the context of professional practice, the clinical teaching internship is an appropriate framework to examine candidate reflection. Specifically, the reflective process spirals through stages of appreciation, action, and re-application (Schön, 1983, 1991). Schön (1983) identified the 
reflective process as being intimately bound with action, for this study, the clinical teaching internship serves as the context for the reflective process.

"As a process, experiential learning is cyclical in nature and requires an initial focus of the learner, followed by interaction with the phenomenon being studied, reflecting on the experience, and then testing those generalizations" (Roberts, 2006, p. 27). The clinical teaching experience serves as the phenomenon of which the teacher candidates are interacting with and reflecting upon. Over the course of the 15-week clinical teaching experience, teacher candidates have daily opportunities to test the generalizations in which they reflected upon, ultimately leading to their outcomes. In the case of SBAE, a three-component model of agricultural education (National FFA Organization, 2015) was developed to outline the integral components of a complete program. The National FFA Organization (2015) identifies the three components as classroom/laboratory instruction, FFA, and Supervised Agricultural Experiences (SAE). Together the three components supported students through the delivery of a complete program, of which, teacher candidates were responsible for conducting during their clinical teaching experience. Candidates experienced each of these components experientially, allowing for reflection on a complete program through the stages of appreciation, action, and re-application (Schön, 1983, 1991). This process further supported the cyclical nature of Schön's (1983) theory, providing a reflective opportunity before re-application. First paragraph: Use this for the first paragraph in a section, or to continue after a long quote.

\section{Purpose of the Study}

The purpose of this study was to explore the value of weekly student teacher video reflections during the teaching internship. Researchers aimed to gain a deeper level of reflection from teacher candidates completing a 15-week teaching internship. To achieve our purpose, weeks three, seven, and 11 were selected for review during the experience. Two objectives guided this study: (1) Analyze the reflective nature of the teacher candidate's weekly reflections; (2) Determine to what extent do teacher candidates reflect on a complete SBAE program during the clinical teaching internship?

\section{Methods and Procedures}

For this exploratory study, a qualitative lens was implemented to uncover the perceptions of pre-service teacher candidates at OSU from the spring 2019 cohort $(\mathrm{N}=$ 16). The 15-week clinical teaching internship served as our case (Stake, 2000). Each teacher candidate was responsible for uploading a weekly video featuring a reflection of the clinical teaching experience. Candidates were asked to create a five-minute video using Swivl, a cloud-based, subscription tool that supports collaborative video data capture and sharing. These videos were then to be viewed by their respective university supervisor for each of the 15 -weeks. 


\section{Sampling Procedure}

A purposive sampling method was employed identifying six candidates or cases to be used for the study. Cases represented different combinations of pairings available to the researchers i.e., out-of-state clinical teaching; in-state clinical teaching; undergraduate students; graduate student; placement in a single teacher program; and placement in a multiple teacher program. This purposive sampling technique was implemented as the participants mirrored the current gender demographic reflected in the teacher preparation program at OSU i.e., four females and two males. The six teacher candidates served as a representative population for this exploratory study.

In addition to selecting participants $(n=6)$, the researchers identified three points in time i.e., weeks three, seven, and 11 to analyze for the study. The three weeks selected represented a pivotal point in the clinical teaching experience. Week three allowed student teachers to become acclimated to their center and cooperator, along with the first complete week of teaching at least one class. During week seven, student teachers were charged with teaching multiple courses and preparing for livestock events. Week 11 provided a full teaching load, while also being challenged with preparing FFA career development event (CDE) teams for the national qualifying CDE event.

\section{Research Team}

The research team consisted of three members: an agricultural education faculty member, instructor, and graduate student completing a Ph.D. in agricultural education. All team members were previously SBAE teachers with a combined 30 years of secondary teaching experience and currently serve as university supervisors for teacher candidates, making them knowledgeable and credible regarding the student teaching internship (Privitera, 2017). With the research team being immersed in the data as part of their day to day job, in addition to purposeful research, bias and subjectivity present potential risk to trustworthiness (Creswell, 2012), therefore the case study method was implemented. Implementing this method while watching the student-teacher reflection videos, allowed each case to speak for itself (Stake, 2000).

\section{Qualitative Analysis}

The six individual cases were analyzed as a collective case study (Stake, 2000). The analysis resulted in three rounds of qualitative coding. Round one provided the researchers an opportunity to individually watch the videos while taking observational notes (Glesne, 2016) on thoughts, concepts, and emerging themes within each video (Saldaña, 2016). The second round resulted in the comparison of data from the researchers, providing an opportunity to improve trustworthiness by developing interrater reliability and member checking among the researchers (Creswell, 1998; Privitera, 2017). This collaboration resulted in harmonized codes and categories (Saldaña, 2016) for each of the six candidates during the three chosen weeks. The final step in the coding process was to take the codes and categories from each teacher candidate and identify the emerging themes (Glasser \& Strauss, 1967) for each of the identified weeks. These 
themes were then buttressed against the three-component model of agricultural education (National FFA, 2015) to determine the perceptions of each of those integral areas of a complete SBAE program during the clinical teaching internship to answer the second research question.

\section{Trustworthiness}

The trustworthiness of this qualitative study was of great importance to the researchers, striving to maintain rigor and uphold the quality of findings. Therefore, the trustworthiness criteria from Creswell (1998) were followed i.e., prolonged engagement, triangulation of data, rich descriptions, negative case analysis, member checking, bias, and subjectivity. Triangulation of data is a major part of developing trustworthiness, which Glesne (2016) defines as "using multiple data-collection methods, multiple sources, [and/or] multiple investigators" (p. 53).

For the triangulation of data, three researchers and two additional collection methods and sources were utilized (Glesne, 2016). Student-teacher weekly reports and a focus group interview with the Spring 2019 clinical teaching cohort $(N=16)$ served as the additional sources for triangulation. The weekly reports were used to determine the time spent weekly in classes, preparing to teach, and involvement in FFA and SAE through a content analysis of the candidate created documents. The weekly reports for the six teacher candidates selected were evaluated from weeks three, seven, and 11 to align with the video reflections observed, resulting in 18 weekly reports to buttress against the collective case videos.

In addition, during the capstone seminar, while the cohort was on campus, the research team conducted a focus group interview with all 16 teacher candidates. During this focus group interview, candidates were asked to reflect and discuss their experiences during week three, seven, and 11, while also considering their growth throughout the 15week experience. The key concepts and themes discussed during the focus group were written on whiteboards for the research team to then compare against the emerging categories and themes developed from the previous analysis of the reflection videos and weekly reports. Additionally, the focus group provided a platform for the researchers to compare the findings from the six teacher candidates against the complete cohort $(N=$ 16) for member checking of data (Creswell, 2012). The findings of this exploratory study are intended to inform practice for the teacher preparation program at OSU and could be transferable to peer institutions.

\section{Findings}

The first objective of this study was to analyze the weekly reflections during the 15-week clinical teaching internship. The first reflection videos featured week three of the clinical teaching internship. Per the suggested timetable created by OSU, candidates should be settled into a routine within the cooperating center and teaching at least one class. Overall, the teacher candidates $(n=6)$ were positive in their reflection videos, discussing challenges and accomplishments for the week and focused primarily on basic 
classroom instruction. The emerging theme for week three was establishing roles as a teacher (see Table 1). The emergence of this theme came from six overarching categories, including, building relationships, team teaching, student/classroom management, planning, teaching load, and balance.

Building relationships dealt with the relationships developed with the cooperating teacher(s), students, and administration. Stemming from codes such as, "getting to know students," "meeting admin," and "student interest inventory to determine interest and build relationships." Team teaching was established from codes including "developing lessons with cooperator," "co-teaching," and "team teaching." Student/classroom management emerged from student teachers saying, "I feel like its teacher vs. teenage boys," "students won't take me seriously," and "issues during CDE practices." Reflections from student teachers like "I need to plan," "need lesson plans for CDE practices," and "planning while traveling," led to planning as a category. The teaching load during week three was highlighted as "teaching one class," "I have two equine classes," and "teaching the freshman class," which were supported in the written weekly report, with the student teachers having control of one to two classes at this time. The concept of balance was represented by "I am putting in too many hours," "I am struggling with guilt," "going on SAE visits," "prepping for the local show," and "coaching CDE teams after school." The time spent in all these additional areas was reflected in written reports, with documentation of as many as 20 hours outside the classroom for FFA and SAE opportunities during week three. During the student-teacher focus group $(N=16)$ emerging topics of discussion included struggling to balance the responsibilities, exhaustion from long hours, beginning to be accepted as a teacher, and the realization of the teaching roles in SBAE. The findings of the focus group support the findings of the research teams' categories and themes from the weekly reflection videos (see Table 1).

Table 1. Student Teaching Week Three Themes, Categories, and Codes.

\begin{tabular}{|c|c|c|}
\hline Theme & Categories & Codes \\
\hline \multirow[t]{2}{*}{$\begin{array}{l}\text { Establishing roles as a } \\
\text { teacher }\end{array}$} & Building relationships & $\begin{array}{l}\text { Getting to know students } \\
\text { Meeting administration } \\
\text { Building relationships with } \\
\text { cooperating teacher } \\
\text { Went to a girls' basketball game } \\
\text { Building rapport } \\
\text { Continually meeting teachers and } \\
\text { personnel } \\
\text { Student interest inventory to } \\
\text { develop interest and } \\
\text { build relationships }\end{array}$ \\
\hline & Team teaching & $\begin{array}{l}\text { Team teaching } \\
\text { Co-teaching with cooperator } \\
\text { Developing lesson plans } \\
\text { with cooperator }\end{array}$ \\
\hline
\end{tabular}


Eck et al.: Teacher Candidate's Reflection

Student/Classroom management

Planning

Teaching load

Balance
Teacher vs. teenage boys Students not taking me seriously

Issues with students Student issues during CDE practice

Seventh-hour rough class

Need to plan

Need to develop lesson plans for CDE practices Developing lessons while raveling

Planning is challenging Planning/preparing to teach electricity class

Plans change

Teaching one class

Teaching two equine classes

Teaching the seventh hour

Teaching a couple of classes

Teaching freshman class

Putting in too many hours

Struggling with guilt

Heavy CDE practices

CDE practices during class

SAE project visits

Local show prep

After school practice

Note. Table 1 highlights the individual second-round categories, which resulted from individual first-round codes, leading to harmonized week-three themes.

Week seven provided an opportunity for candidates to experience teaching multiple classes, participating in livestock shows, and preparing for CDEs. Although the overall feel was still positive, the time and effort needed to be an SBAE teacher were becoming apparent in the videos, with emerging themes of teaching and learning and balance. The theme of teaching and learning came from the development of categories supporting formal and informal teaching in an SBAE program. Formal teaching was supported by "teaching multiple classes," "feeling more confident," "using CIMC and iCEV to prepare," and "using a variety of methods." CIMC and iCEV are curriculum resources which are provided to the teacher candidates at OSU as a teaching and planning tool for their clinical teaching experience. Whereas informal teaching was supported by "teaching in the barn," "prepping CDE teams," and "engaging with students at the livestock show." The findings from the teaching and learning theme were supported by 
the time commitments and weekly plans demonstrated in the week seven written report, along with the conclusions from the focus group. The focus group elaborated on the understanding of lesson planning and the utilization of resources to plan. The candidates also felt they had grown significantly in their comfort level to teach and prepare CDE teams at this point in the experience.

Balance emerged from three categories, including long hours, balancing time, and personal wellness. Codes supporting the long hours included "week was a blur," "put in a lot of extra hours this week," and "long days at livestock shows." These long hours led to the need to balance time, where codes such as "it is difficult to manage not being here," "feel like I am not teaching enough," and "this is chaos, not being in the classroom much this week" supported this category. Additionally, codes like "I am sick," "slow and groggy," and "I am slowly watching my cooperator kill herself," supported personal wellness. See Table 2 for a complete depiction of the individual codes, categories, and emerging themes. These long hours and extra efforts were recorded in the week seven written report and discussed during the focus group interview, as the chaos was brought up from the long hours of before and after school CDE practices and time out of the classroom. The triangulation of data sources supports the themes of teaching and learning and balance for week seven.

Table 2. Student Teaching Week Seven Themes, Categories, and Codes.

\begin{tabular}{|c|c|c|}
\hline Themes & Categories & Codes \\
\hline \multirow[t]{2}{*}{$\begin{array}{l}\text { Teaching and } \\
\text { learning }\end{array}$} & Formal teaching & $\begin{array}{l}\text { Hands-on lesson plans } \\
\text { Project-based learning } \\
\text { Teaching multiple classes } \\
\text { Using realia } \\
\text { Individual and group projects } \\
\text { Motivational games } \\
\text { CIMC and iCEV to plan } \\
\text { Teaching hydroponics } \\
\text { Using a variety of methods } \\
\text { Feeling more confident in the } \\
\text { classroom }\end{array}$ \\
\hline & Non-formal teaching & $\begin{array}{l}\text { Teaching in the barn } \\
\text { Prepping CDE teams } \\
\text { Parli Pro practice } \\
\text { Horse judging team } \\
\text { Livestock show was a laid back } \\
\text { learning environment } \\
\text { Livestock team }\end{array}$ \\
\hline Balance & Long hours & $\begin{array}{l}\text { I put in a lot of extra hours } \\
\text { The week was a blur } \\
\text { Extra practices, long hours } \\
\text { Long days at livestock shows } \\
\text { Busy week } \\
\text { Too tired to write lesson plans }\end{array}$ \\
\hline
\end{tabular}


Balancing time

Personal wellness

Difficult to manage not being

here

Chaos

Feel like I am not teaching

Four contest this week

Attended out of state contest

Been in the barn all week

I am sick

Have the barn crud

Groggy and slow

Slowly watching my cooperator kill herself

Note. Table 2 highlights the individual second-round categories, which resulted from individual first-round codes, leading to harmonized week-seven themes.

Week 11 involves teaching full course loads, coaching CDE teams, preparing for banquet, and state FFA convention. Teacher candidates were excited, having fun, and looking forward to the future, as some had accepted employment as an SBAE teacher, while others were on the job hunt. Emerging from the videos was a culmination of factors associated with teaching SBAE, resulting in a theme of coming full circle. This theme was supported by categories of confidence, teaching in all settings, balance, and personal wellness. Confidence emerged as "feeling accomplished," "students are really learning," "kids are excited," "I look forward to each day," and "I finally feel confident." Teaching in all settings developed from "coaching CDE teams," "teaching at contests," "conducting SAE visits," "teaching in the greenhouse" and "teaching before, during, and after school." Balance emerged for the third time although codes changed to "busy but good," "having the opportunity to go on overnight trips," and "late nights, but kids are learning." Personal wellness resurfaced in week seven, although now the codes of "stressed," "anxious," and "tired" were because the hunt for SBAE jobs was stressful. Table 3 outlines the themes, categories, and individual codes for week 11. The findings for week 11 were supported by written reports documenting a full teaching load and FFA and SAE opportunities. The focus group felt confident in week 11 and said they finally reached a point of enjoyment and understood how to reach the students and make an impact, although the stress levels were high as they were interviewing, negotiating, and accepting positions as SBAE teachers.

Table 3. Student Teaching Week 11 Themes, Categories, and Codes.

\begin{tabular}{lll}
\hline Themes & Categories & Codes \\
\hline $\begin{array}{l}\text { Coming full } \\
\text { circle }\end{array}$ & Confidence & Feeling accomplished \\
& & Students are learning
\end{tabular}




\begin{tabular}{|c|c|}
\hline & $\begin{array}{l}\text { Kids are excited } \\
\text { Teams are getting better } \\
\text { Good experiences } \\
\text { Fun week } \\
\text { I look forward to each day } \\
\text { Feel confident in the lesson } \\
\text { planning }\end{array}$ \\
\hline Teaching in all settings & $\begin{array}{l}\text { Teaching in class } \\
\text { Coaching CDEs } \\
\text { Teaching at contests } \\
\text { Teaching full load } \\
\text { Contests provide an } \\
\text { opportunity to engage } \\
\text { and develop students } \\
\text { Teaching before, during, and after } \\
\text { school } \\
\text { Engaging students } \\
\text { SAE visits } \\
\text { Teaching in the greenhouse }\end{array}$ \\
\hline Balance & $\begin{array}{l}\text { Crazy hours } \\
\text { Late nights } \\
\text { Overnight trips } \\
\text { Speech contests } \\
\text { CDE contests } \\
80+\text { hours this week } \\
\text { Busy and good }\end{array}$ \\
\hline Personal wellness & $\begin{array}{l}\text { Anxious } \\
\text { Stressed } \\
\text { Tired, but close to the end } \\
\text { Stressful }\end{array}$ \\
\hline
\end{tabular}

Note. Table 3 highlights the individual second-round categories, which resulted from individual first-round codes, leading to harmonized week 11 themes.

Overall, the three different weeks analyzed provided a valuable snapshot of teaching candidates' perceptions of the 15-week clinical teaching internship. The focus group interview $(N=16)$ supported these weeks as major milestones within the student teaching internship.

To address the second research objective, which aimed to determine the extent to which teacher candidates reflected upon a complete SBAE program during the clinical teaching internship, the emerging codes, categories, and themes were buttressed against the three-component model of agricultural education (National FFA Organization, 2015). The codes, categories, and themes presented in Tables 1 through 3 support the three components of agricultural education set forth by the National FFA Organization (2015), resulting in codes supporting a complete experience for pre-service teacher candidates based on their reflective videos observed in this qualitative case study (see Figure 1). The 
Figure 1. Alignment of Themes with the Three-Component Model of Agricultural Education. Adapted from Three-Component Model of Agricultural Education, by National FFA, 2015.

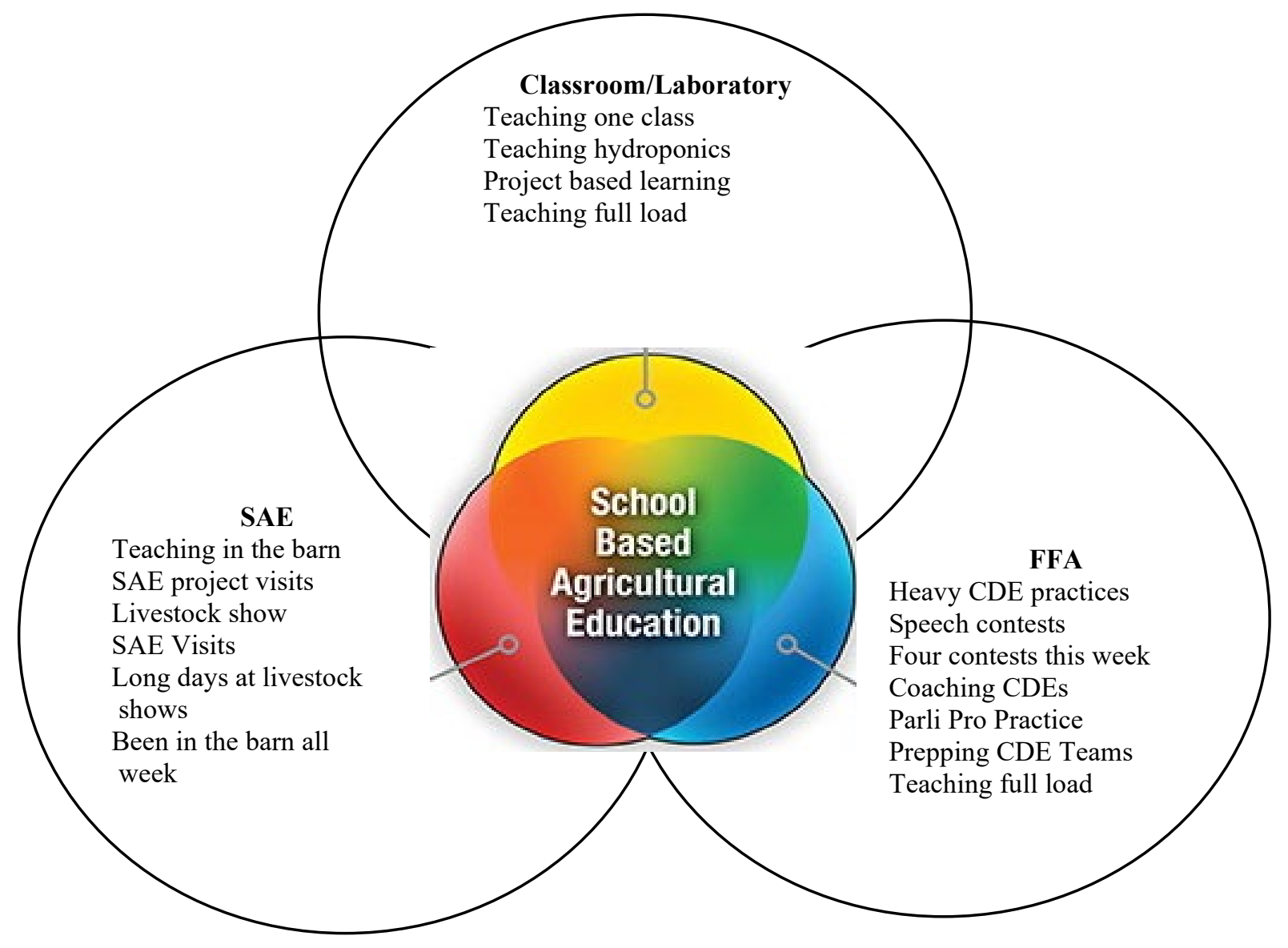

alignment with the three-component model of agricultural education (National FFA Organization, 2015) was evident across cases in this inquiry, with multiple codes supporting each component emerging from the reflection videos of the pre-service teacher candidates.

\section{Conclusions}

This study explored the integration of video reflection during the 15 -week clinical teaching internship. The research team concluded the integration of video allowed candidates an open platform for reflection on their student teaching experience resulting in high quality, in-depth reflections, providing university supervisors with valuable weekly reflections. Four overarching themes emerged from the reflection process: week three, establishing roles as a teacher; week seven, teaching and learning, and balance; and coming full circle in week 11 . These overarching themes supported 15 categories. 
The category of balance emerged in all phases of the study, supporting the findings of Eck et al. (2019) who reported balance as an essential component to effective teaching in SBAE. The growth demonstrated by the teaching candidates through video reflection over the 15-week clinical teaching internship aligns with the cyclical process of experiential learning through the phases of appreciation, action, and re-application (Schön, 1983, 1991). The three stages (Schön, 1983) were evident in the 15-week experience and were showcased in the three chosen weeks that were analyzed within the study. The phase of appreciation was highlighted in week three as candidates began their experience, while week seven proved to be an action-oriented time as they were in the full swing of classroom teaching, CDEs, and SAEs. Week 11 resulted in this feeling of accomplishment and the willingness to continue teaching while further engaging students with less stress, which is supported by Schön's (1983) theory in the form of reapplication.

Growth of the candidates is reflected in their video in a multitude of ways, but overarchingly the codes reflected an experience that provided a culminating learning experience that has prepared them for their future careers as SBAE teachers. These are concepts and reflections that were not previously represented in written weekly reports at OSU, therefore the integration of video reflections during the student teaching internship improved the quality of teacher candidate reflection. Similarly, Sorensen et al. (2018) identified the first few weeks of the clinical teaching internship as "chaos and instability" for the pre-service teachers, while week seven was categorized as "tasks and balance" (p. 115). Although Sorensen et al. (2018) only looked into the first part of the clinical teaching internship, their findings from the first few weeks and week seven aligned with the findings of this study. The early weeks served as a big adjustment for teacher candidates. Feelings of being overwhelmed and inadequate were frequently described. However, by week seven, teacher candidates reported feeling less overwhelmed, with a sense of balance and purposeful engagement.

The second research question aimed to determine the extent to which the video reflections focused on a complete SBAE program. Throughout the 15-week internship, candidates expressed a deeper understanding of teaching within the three-component model of SBAE (National FFA, 2015), which was evident through codes like "teaching at contests" and "coaching CDEs" representing the FFA component, while "long days at livestock shows" and "SAE project visits" represented the SAE component, and "teaching full course load" and "teaching in the greenhouse" spoke to the classroom/laboratory component (see Figure 1). Coming full circle throughout the 15week internship led to codes like "teaching before, during, and after school" supporting the overlap of the three components as integral parts of a complete SBAE program. "Experiential learning is a cyclical process" (Roberts, 2006, p. 27) of which the reflection process serves a key action role (Schön, 1983). Demonstrating the potential of reflection in providing a greater depth of understanding for teacher candidates coming full circle throughout the clinical teaching experience.

The findings of this study met the call of Sorensen et al. (2018) related to clinical teaching reflections "encompassing the entire [clinical] teaching experience" (p. 115). Implications from this study include cooperating teacher/student-teacher pairing and the 
support network during the clinical teaching experience. Researchers noted as a whole, student teachers had a positive and enjoyable clinical teaching experience. This included out-of-state students who student-taught within Oklahoma. Researchers also noted the out-of-state student teacher who performed their clinical teaching experience within their home state expressed an added level of anxiety, frustration, and discontent due to being disconnected from their cohort group. This was of significance since they were "home" and close to the family yet did not feel they had the structured support the rest of their cohort members experienced in Oklahoma. The need for purposeful student-teacher internship pairings (Fosnot, 1996) and the relationships developed (Jones et al., 2014) is further supported by this study. Although not of significance to the research questions, the candidates voiced the overall value they felt of the video reflections during the focus group interviews. In addition to university supervisors watching the weekly reflection videos, the teacher candidates could also watch peer videos as time permitted. The candidates seemed to prioritize this time to watch each other's weekly reflection videos, as they felt a greater sense of community and not being in this experience alone, which was not an initial intent of the integration of the video reflection process. Overall, the addition of the video reflection process has provided an opportunity to establish a more efficient and effective teacher preparation program (Roberts et al., 2016).

\section{Recommendations}

The video reflection process during the clinical teaching experience at OSU will continue with future cohorts as reflective practice to the experiential process (Schön, 1983) of the clinical teaching experience. One practical recommendation features the creation of a structured guide i.e., victories, challenges, and goals to the video reflection process for the teacher candidates to follow. It is also recommended that teacher preparation programs consider the weekly video reflection process as an alternative to writing weekly reflection during the clinical teaching experience. Suggestions for future research include adding quantitative measures to the video reflection component to identify potential stress points within the 15-week clinical teaching experience. Additional research opportunities focus on replicating this line of inquiry with larger clinical teaching cohorts. Teacher preparation programs should consider replicating this study with the implementation of the video reflection process to help determine the impact for their students.

Finally, findings related to balance bear further investigation. The mental health and physical wellness of SBAE teachers should be of concern to state staff, state teacher associations, and teacher educators. Quantitative and qualitative studies should focus on the culture of SBAE to identify potential stressors along with strategies to mitigate unhealthy work practices.

\section{References}

Council for the Accreditation of Educator Preparation. (2013). The CAEP standards. http://caepnet.org/standards/introduction 
Creswell, J. (2012). Qualitative inquiry and research design: Choosing among five approaches (3rd ed.). Sage.

Dewey, J. (1933). How we think: A restatement of the relation of reflective thinking to the educational process. Heath.

Eck, C. J., Robinson, J. S., Ramsey, J. W., \& Cole. K. L. (2019). Identifying the characteristics of an effective agricultural education teacher: A national study. Journal of Agricultural Education, 60(4), 1-18. https://doi.org/10.5032/jae.2019.04001

Epler, C. M., Drape, T. A., Broyles, T. W., \& Rudd, R. D. (2013). The influence of collaborative reflection and think-aloud protocols on pre-service teachers' reflection: A mixed methods approach. Journal of Agricultural Education, 54(1), 47-59. https://doi.org/10.5032/jae.2013.01047

Fosnot, C. T. (1996). Constructivism: Theory, perspective, and practice. Teachers College Press.

Glasser, B. G., \& Strauss, A. L. (1967). The discovery of grounded theory: Strategies for qualitative research. Aldine.

Glesne, C. (2016). Becoming qualitative researchers: An introduction (5th ed.). Pearson.

Giovannelli, M. (2003). Relationship between reflective disposition toward teaching and effective teaching. The Journal of Educational Research, 96(5), 293-309. https://doi.org/10.1080/00220670309597642

Greiman, B. C., \& Covington, H. K. (2007). Reflective thinking and journal writing: Examining student teachers' perceptions of preferred reflective modality, journal writing outcomes, and journal structure. Career and Technical Education Research, 32(2), 115-139. https://doi.org/10.5328/CTER32.2.115

Hunter, R. (2004). Madeline Hunter's mastery teaching: Increasing instructional effectiveness in elementary and secondary schools. Corwin Press.

Jones, C. K., Kelsey, K. D., \& Brown, N. R. (2014). Climbing the steps toward a successful cooperating teacher/student mentoring relationship. Journal of Agricultural Education, 55(2), 33-47. https://doi.org/10.5032/jae.2014.02033

Lambert, M. D., Sorensen, T. J., \& Elliott, K. M. (2014). A comparison and analysis of preservice teachers' oral and written reflections. Journal of Agricultural Education, 55(4), 85-99. https://doi.org/10.5032/jae.2014.04085

National FFA Organization. (2015). Three-component model of agricultural education. https://www.ffa.org/agricultural-education/

Privitera, G. J. (2017). Research methods for the behavioral sciences (2nd ed.). Sage.

Retallick, M. S., \& Miller, G. (2007). Early field experience documents in agriculture education. Journal of Agricultural Education, 48(4), 20-31. https://doi.org/10.5032/jae.2007.04020

Roberts, T. G. (2006). A philosophical examination of experiential learning theory for agricultural educators. Journal of Agricultural Education, 47(1), 17-29. https://doi.org/10.5032/jae.2006.01017

Roberts, T. G., Harder, A., \& Brashears, M. T. (Eds). (2016). American Association for Agricultural Education national research agenda: 2016-2020. Department of Agricultural Education and Communication.

Rodgers, C. (2002). Defining reflection: Another look at John Dewy and reflective thinking. Teachers College Record, 104(4), 842-866. https://doi.org/10.1111/1467-9620.00181

Saldaña, J. (2016). The coding manual for qualitative researchers (3rd ed.). Sage.

Schon, D. A. (1983). The reflective practitioner: How professionals think in action. Basic Books.

Schon, D. A. (1991). The reflective practitioner: How professionals think in action. Ashgate Publishing. 
Sorensen, T. J., Lawver, R. G., Hopkins, N., Jensen, B., Dutton, C., \& Warnick, B. K. (2018). Preservice agriculture teachers' development during the early phase of student teaching. Journal of Agricultural Education, 59(4), 105-119. https://doi.org/10.5032/jae.2018.04105

Stake, R. (2000). Case studies. In N. Denzin \& Y. Lincoln (Eds.), Handbook of qualitative research (2nd ed., pp. 435-454). Sage. 